\title{
Analysis of river bed variation using SSARR and RMA-2 models
}

\author{
Ju Ha Hwang ${ }^{1}$ D, Seung Jin Maeng ${ }^{1 *}$, Hyung San Kim² and Seung Wook Lee ${ }^{3}$
}

\footnotetext{
* Correspondence: maeng@cbnu.ac. $\mathrm{kr}$

${ }^{1}$ Department of Agricultural and Rural Engineering, Chungbuk National University, 1 Chungdae-ro, Seowon-gu, Cheongju, Chungbuk 28644, South Korea

Full list of author information is available at the end of the article
}

\begin{abstract}
Future changes in river bed were predicted under the assumption that flow velocity of past and changes in flow rate at upstream river due to construction of large-scale artificial structures downstream occur in the future. Therefore, the long-term runoff volume from the downstream part of Hosan Stream was estimated using the SSARR (Stream Synthesis and Reservoir Regulation Model). Changes in the river bed were simulated using RMA-2 and SED-2D, which are hydraulic models. As a result, it was found that the river bed variation is significantly affected by the inclusion of sediment in flood flow at upstream. A comprehensive evaluation of above results revealed that the river width has significantly affected flow rate, and the inclusion of sediment in flood flow from the upstream has a huge effect on changes in the riverbed. In this regard, there is a need to devise measures to mitigate future flood damage to artificial structures by reflecting sedimentation trends downstream before the construction of large-scale artificial structures at downstream of river.
\end{abstract}

Keywords: Precipitation-discharge, SSARR, Lumped model, Numerical model, River bed variation

\section{Introduction}

These days, the irrigation facilities and the facilities in the vicinity of river are classified into different categories and managed based on the purpose of low flow (occurs mostly in winter season) and high flow (occurs mostly in summer season/monsoon season), and are constructed according to the plans designed to maximize economic effects. Both hydrologic analysis and hydraulic analysis need to be conducted as part of preliminary basic investigation and analysis before these facilities are installed. The hydrologic analysis has been taken to an advanced level through many applications. On the other hand, the hydraulic analysis was based on hydraulic model experiment and therefore much difficulty was involved in its application in Korea. However, the advancement of computers in contemporary era has helped resolve those problems to some degree, enabling the hydraulic properties to be analyzed based on numerical model.

The model commonly used for the experiment of numerical model is the HEC-RAS (Hydrologic Engineering Center-River Analysis System), the 1-Dimensional Gradually Varied Unsteady Flow, which has the advantage of both easiness in model application and usability of survey data. In fact, the 1-dimensional analytical method is applied to the most river basic fundamental planning. Hongwei et al. (2008) used onedimensional numerical model capable of calculating total-load sediment transport.

(c) The Author(s). 2020 Open Access This article is distributed under the terms of the Creative Commons Attribution 4.0 International License (http://creativecommons.org/licenses/by/4.0/), which permits unrestricted use, distribution, and reproduction in any medium, provided you give appropriate credit to the original author(s) and the source, provide a link to the Creative Commons license, and indicate if changes were made. 
However, the 2-dimensional model needs to be applied to meet the engineering need for more elaborate free analysis, such as the analysis in conjunction with the river bed variation analysis, 2-dimensional water quality analysis, analysis of the changing pattern of local flow based on the variation of channel flow or analysis in case that various hydraulic facilities - such as bridge, weird, etc. - exist or in case of the confluence where a tributary joins the channel.

The hydrological model tends to be divided into lumped model and distributed model. This study investigated application cases with a focus on distributed model due to the limitations of input data. Narut (1978) analyzed the characteristics of parameters by using SSARR model and how each parameter works in runoff. Lee and Kim (2001) applied the SSARR model to the Nakdong River watershed, exhibited the excellence of seasonal discrimination using a Genetic Algorithm (GA) for calibrating parameters and presented the advantages of flow calculations. Jeong et al. (2006) presented basic data necessary for figuring out the scale of water supply from the Hwacheon Dam and operating the dam in the future using the SSARR model through the identification of runoff characteristics based on past hydrological data (1998-2005). Lee et al. (2009) estimated and verified the long-term runoff volume using the SSARR model as well as hydrological, spatial information in a small catchment of the Geum River watershed. Based on their data, reliable hydrological information in connection with rainfall-runoff management module was presented.

With regard to researches on numerical analysis, Han et al. (1993) studied effects of rising water levels due to obstacles resulting from riverbed slope, flow coefficient and roughness coefficient using the BPR (Bureau of Public Road) method. The law of energy conservation is applied to analyze the effects of rise in water levels caused by bridges during flooding. Jeong et al.(2006) calculated a new expression for the transverse riverbed slope by applying linear relationship and exponential relationship equations.

Song et al. (1994) conducted an analysis by applying existing transverse riverbed slope prediction models to river bend of selected watershed and apex potion of bend for estimation of transverse riverbed slope at channel bends. Maeng and Lee (2007) analyzed the hydraulic properties on the downstream of Hwacheon Dam to select a point where fish ladders are installed in Hwachon Dam downstream.

Nagata et al. (2000) has developed a 2D sediment model for banks of river. Hung et al. (2009) developed an unsteady 2D depth-averaged model, applied at alluvial channels where there is no uniformity in sediment transport. Duan and Julien (2010) applied 2D numerical simulation considering river bed changes, suspended sediment transport and bedload. Li and Millar (2011) developed 2D morphodynamic model of gravel-bed river with floodplain vegetation, considering the effects of riparian and floodplain vegetation on bank strength, floodplain flow resistance, shear stress partitioning, and bedload transport. Serrano-Pacheco et al. (2012) conducted two-dimensional bedload transport simulations, in which bedload transport is computed by a power law of flow velocity and by a flow/sediment interaction parameter.

This study presents a prediction of river bed variation in near future on assumption that the changes in upstream flow rates and past flow rates.

For that, the hydrological analysis of Hosan Stream Basin was conducted first, which was followed by the analysis of hydraulic properties based on the 2-dimensional 
numerical model by using the daily discharge, derived by the hydraulic analysis, and the observation precipitation as the input data.

\section{Selection \& characteristics of the model}

After conducting the hydrological analysis of Hosan Stream Basin watershed to simulate the variations in downstream part of Hosan Stream, the hydrologic characteristics need to be analyzed based on 2-dimensional numerical model by using the daily discharge and observation precipitation, of each river which are obtained by hydrological analysis as the input data. To ensure objectivity of results in this analytical process, it is very important which model to select from many hydrologic models and hydraulic models that have been introduced in Korea and abroad. It requires to be the long-term model from the standpoint of analysis period because the long-term runoff analysis has to be conducted for the hydrological analysis. The lumped model must be selected which makes it relatively easier to obtain the input data than the distributed model which requires the detailed river information from the standpoint of analytical method. Model was selected which was deemed suitable for the purpose of this study and had been used in many cases both in Korea and abroad (Fig. 1). In addition, the 2dimensional model was selected which enabled the simulation of river bed variation characteristics for the analysis of hydraulic characteristics. Both RMA-2 model and SED-2D model, which are GUI (Graphic User Interface)-supported, were selected.

The SSARR model is the model that has been constantly calibrated since its development by the US Army Corps of Engineers (USACE) in 1956, and has been widely used for the purpose of predicting real time daily discharge of large-scale basin, reservoir regulation, etc.

To implement the RMA-2 model, the bed material characterization coefficient and boundary condition must be introduced from finite element grid (Fig. 2). The general boundary condition includes the discharge, velocity of flow, and water level. In addition, there are the $\mathrm{n}$ values of coefficient of roughness of Manning, the coefficient of bed material characteristics, and the eddy exchange coefficient of eddy viscosity term that can indicate the turbulent components based on flow characteristics.

The SED-2D model is continuously modified and refined as the revised edition of STUD-H program which was developed by Ariathurai and Krone (1976). SED-2D model can be simulated for river bed sand and river bed clay, but cannot be simulated for concrete structure. Moreover, the simulation can be conducted for only one representative grain size when effective grain size is considered, and therefore simulation must be performed separately for other effective grain sizes.

The finite element formula for SED-2D model was proposed by Ariathurai and Krone (1976), and can be summarized by the 4 important calculations such as advectiondiffusion equation, bed shear stress, river bed specification, and river bed model.

\section{Characteristics of the concerned basin}

\section{Overview of the basin}

Hosan Stream is the local river and originates from Icheon-ri (most small administrative unit in Korea), Samcheok city. It flows southeast and joins the East Sea. Hosan Stream has the stream length of $20.5 \mathrm{~km}$ and watershed area of $64.8 \mathrm{~km}^{2}$. The stream slope of Hosan Stream is relatively gentle, ranging from 1/58 to 1/195 in the middle 


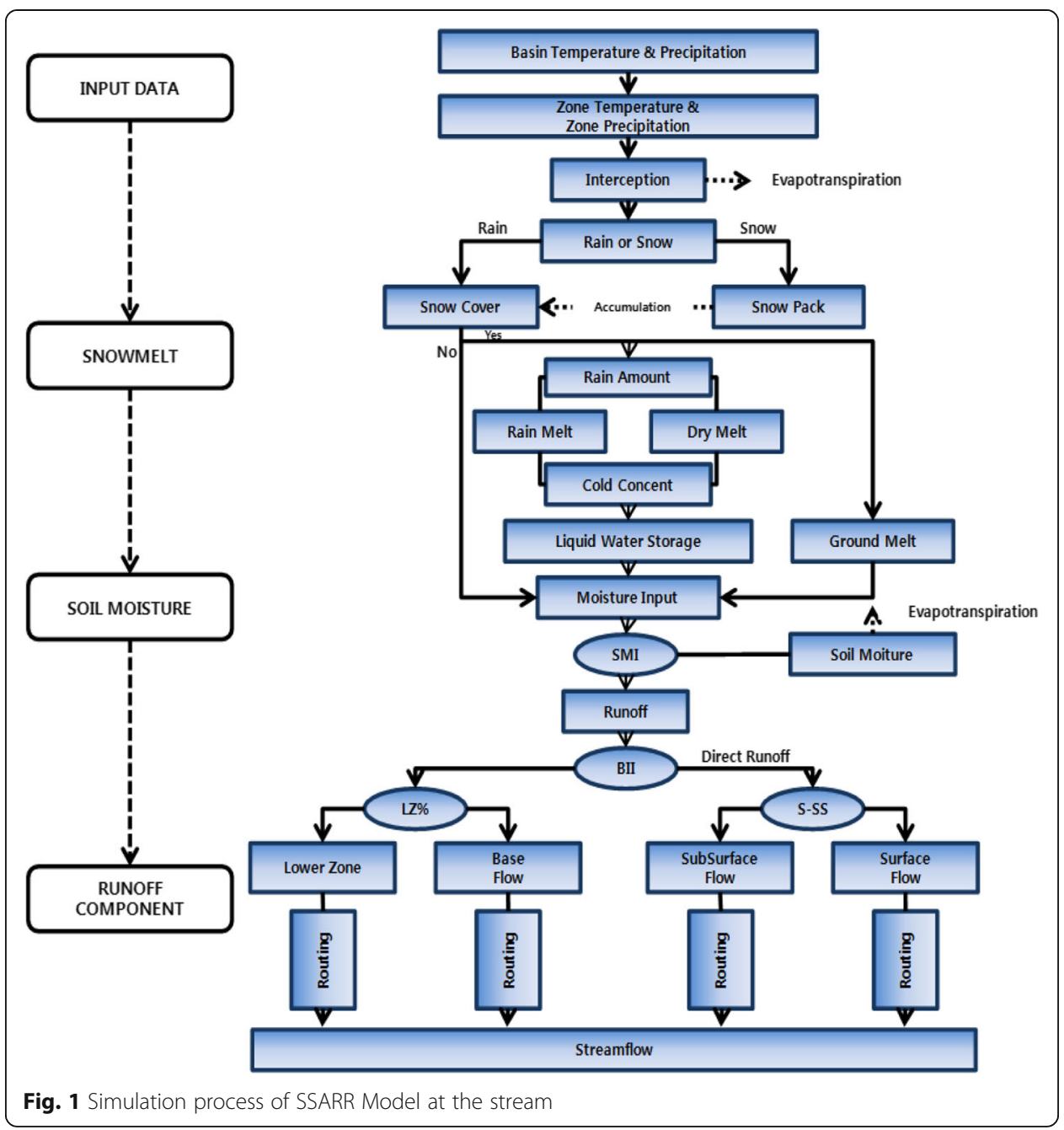

and downstream, while it maintains the mountain stream with relatively steep stream slope ranging between $1 / 17$ and $1 / 28$ in middle and upstream.

\section{Weather \& Climate}

The meteorological observation scope of Uljin Weather Station, which is geographically adjacent, was selected as the survey area in order to determine weather conditions of Hosan Stream Basin. The meteorological characteristics were analyzed based on major meteorological elements by using the meteorological data that have been collected over the last 13 years (from 1999 to 2011). The observation scope of Samcheok city is covered by Donghae Meteorological Agency, but the meteorological data of Uljin Regional Meteorological Office were used because the target area located in the southern part of Samcheok city is closer to Uljin Regional Meteorological Office (Fig. 3).

The temperature data which had been collected by Uljin Regional Meteorological Office over last 13 years (from 1999 to 2011) were investigated. The annual mean temperature was $12.9^{\circ} \mathrm{C}$, while the seasonal temperature was $11.9^{\circ} \mathrm{C}$ in spring, $22.0^{\circ} \mathrm{C}$ in summer, $14.8{ }^{\circ} \mathrm{C}$ in autumn, and $3.0^{\circ} \mathrm{C}$ in winter. The maximum difference in seasonal mean temperature was $19.1^{\circ} \mathrm{C}$. 


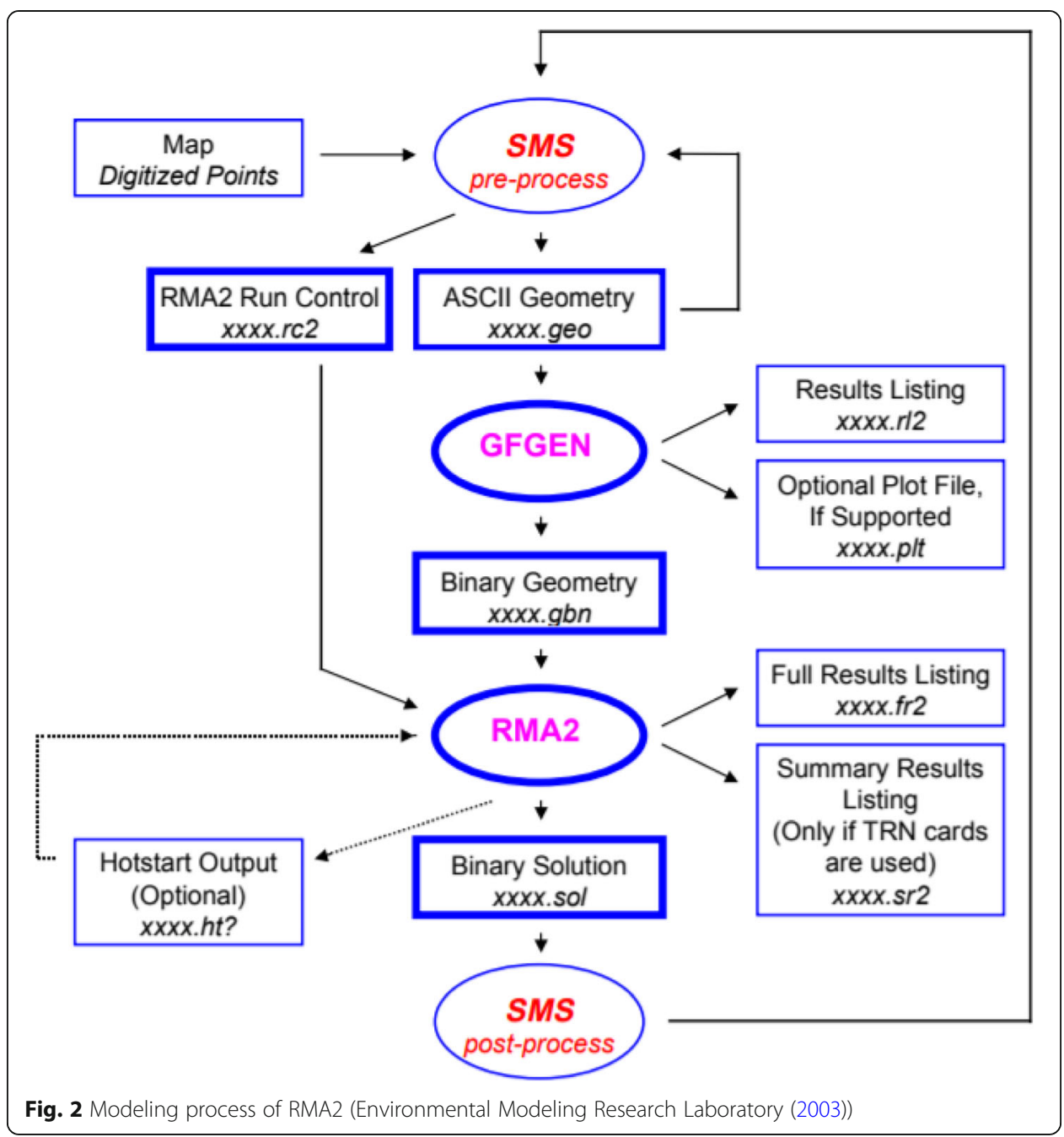

The highest monthly mean temperature was $23.5^{\circ} \mathrm{C}$ in August. The highest monthly temperature was $36.3^{\circ} \mathrm{C}$ in August, while the lowest monthly temperature was $13.3^{\circ} \mathrm{C}$ in January.

As it is important to acquire the long-term precipitation data for the hydrological analysis, the precipitation data of Uljin Regional Meteorological Office were collected for period spanning from 1972, the observation reference year, to 2011. The annual average precipitation was $1096.1 \mathrm{~mm}$. The seasonal distribution of precipitation was $195.6 \mathrm{~mm}$ in spring, $485.6 \mathrm{~mm}$ in summer, $312.9 \mathrm{~mm}$ in autumn, and $102.1 \mathrm{~mm}$ in winter, suggesting high level of precipitation in summer which is consistent with the typical weather trends in Korea, and the precipitation concentration ratio was found to stand at 44.3\% (Korea Meteorological Administration, 2011).

\section{Hydrological analysis}

\section{Physical parameter}

The parameter set in the hydrologic model can be classified into physical parameter, hydrologic meteorological parameter, and internal processing parameter. The parameters 


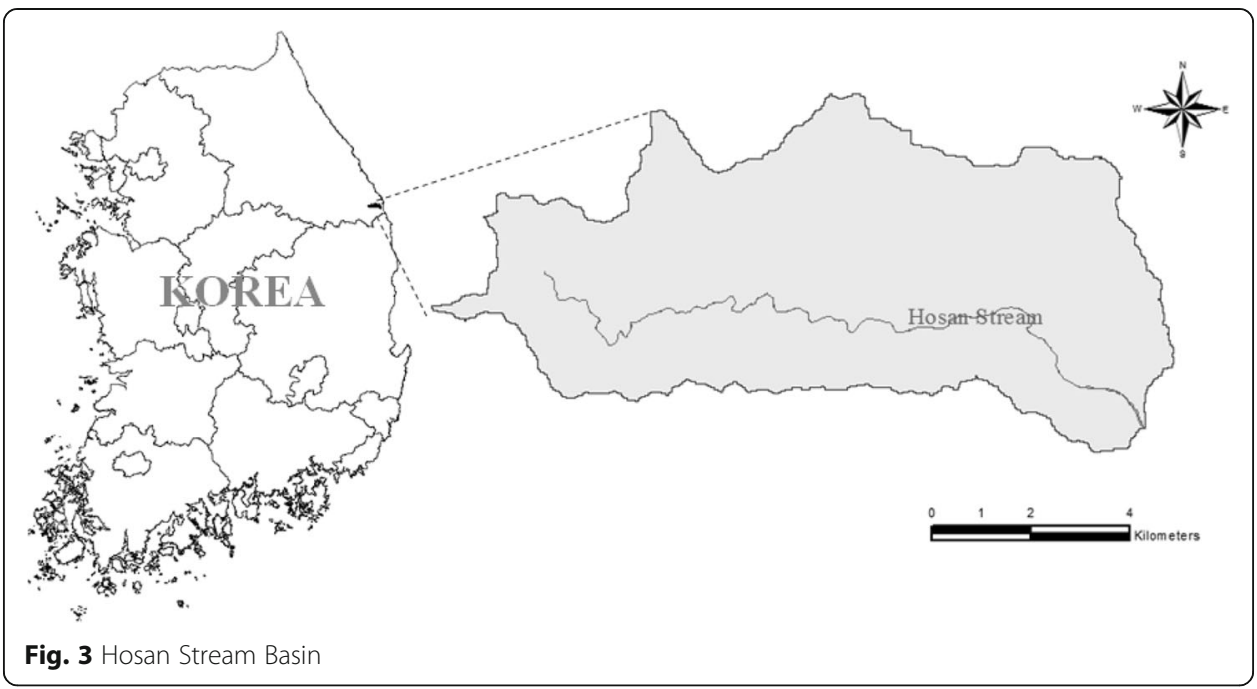

that had to be determined in SSARR model include the hydrologic meteorological input parameter, rainfall and snowfall data, weighed value of index, maximum intercepted amount, and temperature.

\section{Internal processing parameter}

The SMI-ROP, BII-BFP, and S-SS, which are the internal processing parameter of SSARR model, were estimated. The internal processing parameter must be estimated through the calibration with the discharge simulated by SSARR and the discharge observed at the Hosan Stream. However, it is impossible to conduct the calibration through the comparison of SSARR model-based simulation discharge and observation discharge because there is no observation discharge data for the target stream of this study. Thus, this study used the internal processing parameter estimated when the SSARR model was applied to the Pyeongchang River basin which is geographically close to the target basin, has similar physical properties of basin, and generated reliable observation discharge data (Korea Water Resources Corporation 2008). Table 1 presents the SMI (Soil Moisture Index) - ROP (Runoff Percent) BII (Baseflow Infiltration Index)-BFP (Base Flow Percent) and S-SS (Surface-Subsurface Separation) which are the internal processing parameter applied in this study. In addition, the values

Table 1 Internal Processing Parameter

\begin{tabular}{llllll}
\hline SMI (cm) & ROP (\%) & BII (cm/d) & BFP (\%) & S-SS (cm/hr) & $\begin{array}{l}\text { Surface Comp. } \\
(\mathrm{cm} / \mathrm{hr})\end{array}$ \\
\hline 0 & 8 & 0.0 & 40 & 0.0 & 0.00 \\
1 & 30 & 1.0 & 14 & 0.5 & 0.15 \\
2 & 51 & 1.5 & 11 & 1.0 & 0.57 \\
3 & 65 & 2.0 & 10 & 1.5 & 1.07 \\
4 & 81 & 2.5 & 10 & 2.0 & 1.57 \\
5 & 59 & 3.0 & 10 & 2.5 & 2.07 \\
10 & 100 & 5.0 & 10 & 3.0 & 2.57 \\
999 & 100 & 10.0 & 10 & & \\
\hline
\end{tabular}


presented in the SSARR Manual were used as internal processing parameters such as infiltration, storage period, maximum infiltration, maximum ground water discharge ratio, etc. (USACE 1991).

\section{Estimation of simulation discharge}

The daily discharge at the end of Hosan Stream Basin was simulated for the period spanning from 1972 to 2011 based on SSARR model by applying the parameter and input data which were determined. Figure 4 presents the daily mean discharge of Hosan Stream Basin for the period from 1972 to 1980, the period from 1981 to 1990, the period from 1991 to 2000, and the period from 2001 to 2011, and the daily mean discharge for the entire period of analysis.

The years with the maximum, medium, and minimum discharge at Hosan Stream Basin are 2003, 1984, and 1979, respectively, among the daily discharges which were simulated for the period of 4 decades spanning between 1972 and 2011. Moreover, it can be found that the discharge after 2000 was relatively higher than the level recorded before 2000 .

\section{Flow regime analysis}

It is very important to determine the discharge, the input data of RMA-2 model, when the flow velocity distribution and river bed variation characteristics are analyzed for the section of the target stream. Thus, the flow regime analysis was conducted to determine the flood discharge, abundant water discharge, normal flow, low water discharge, and drought flow of Hosan Stream Basin, by applying the discharge of Hosan Stream which was simulated based on SSARR model. The results of analysis showed the flood discharge of $89.5 \mathrm{~m}^{3} / \mathrm{s}$, abundant water discharge of $0.8 \mathrm{~m}^{3} / \mathrm{s}$, normal flow of $0.4 \mathrm{~m}^{3} / \mathrm{s}$, low water discharge of $0.3 \mathrm{~m}^{3} / \mathrm{s}$, and drought flow of $0.2 \mathrm{~m}^{3} / \mathrm{s}$.

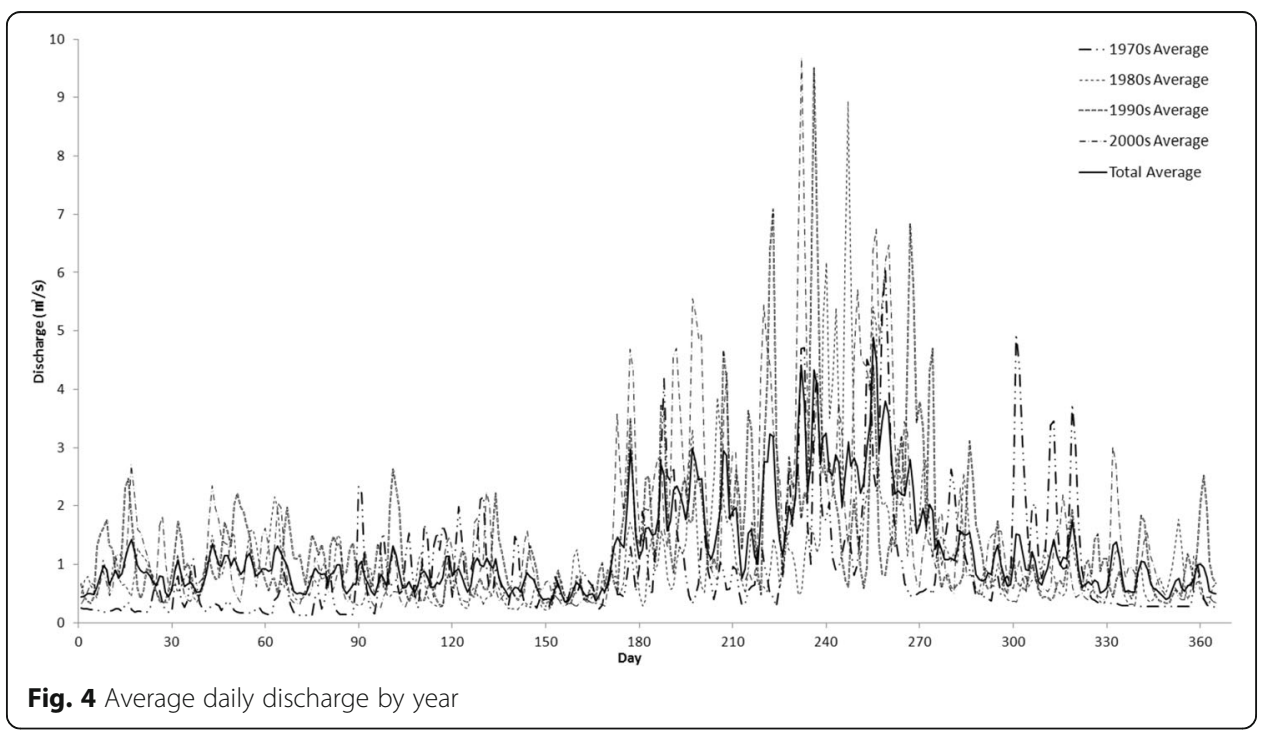




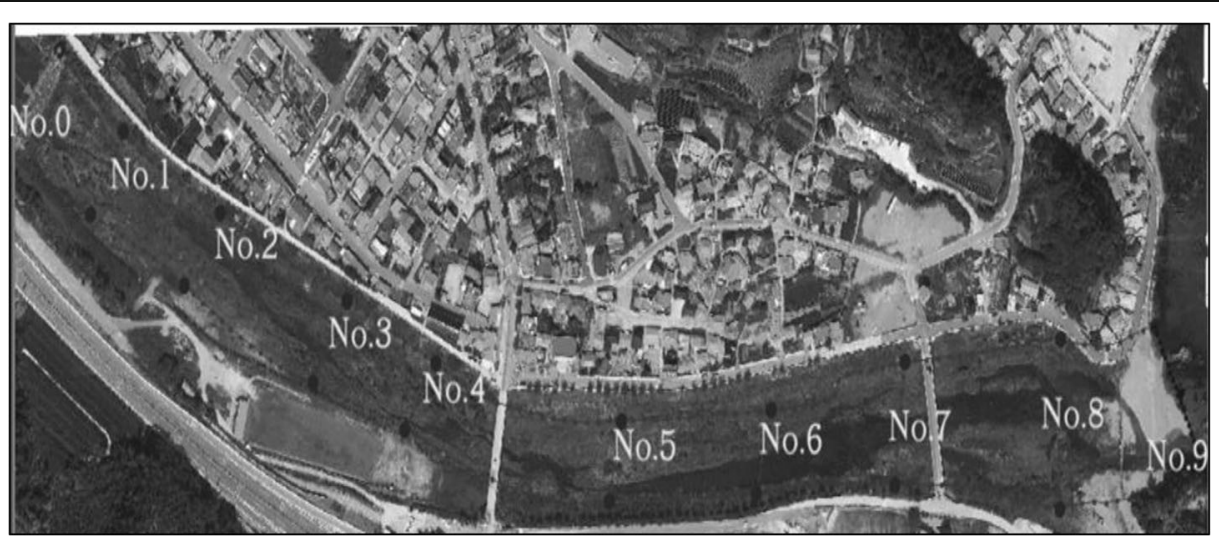

Fig. 5 Map of Current Status of the Analyzed Section

\section{Hydraulic analysis}

\section{Longitudinal \& Cross-Sectional Analysis}

The cross-section of river was divided into 9 sections (from No. 0 to No. 8) as shown in Fig. 5 to determine the shape of river bed and material properties for the simulated target section. The geometric data were arranged as shown in Fig. 6 as the preprocessing process of RMA-2 model in order to analyze the river variation characteristics of the section illustrated in Fig. 5. The grid network was arranged as shown in Fig. 7 by using the geometric data.

\section{Flow velocity distribution}

The discharge, which is the boundary condition for the upstream, was set to $89.5 .0 \mathrm{~m}^{3} / \mathrm{s}$, flood discharge which was determined when flow regime analysis was conducted. The water elevation, the boundary condition for the downstream, was set to elevation (EL). $4.40 \mathrm{~m}$ based on the Trial and Error Method. Water elevation and boundary condition for the downstream, was set to EL. $4.40 \mathrm{~m}$ based on Trial and Error Method. Water elevation and boundary condition of downstream, was set to EL. $4.40 \mathrm{~m}$ based on Trial and Error Method. The coefficient of roughness (unit-less coefficient that changes according

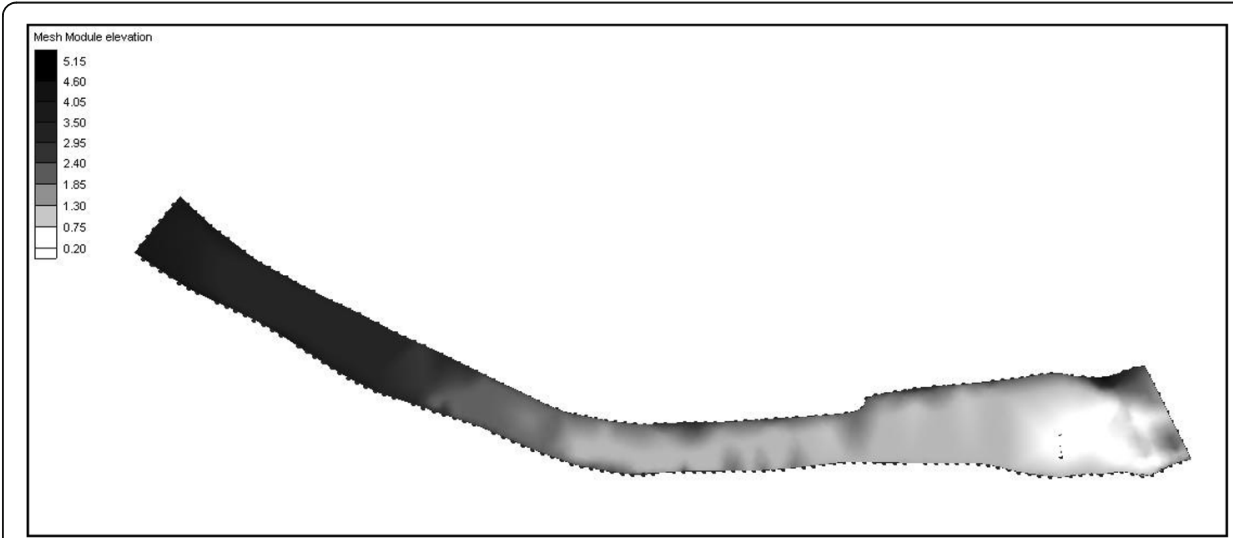

Fig. 6 Arrangement of the Geometric Data for the Analyzed Section 


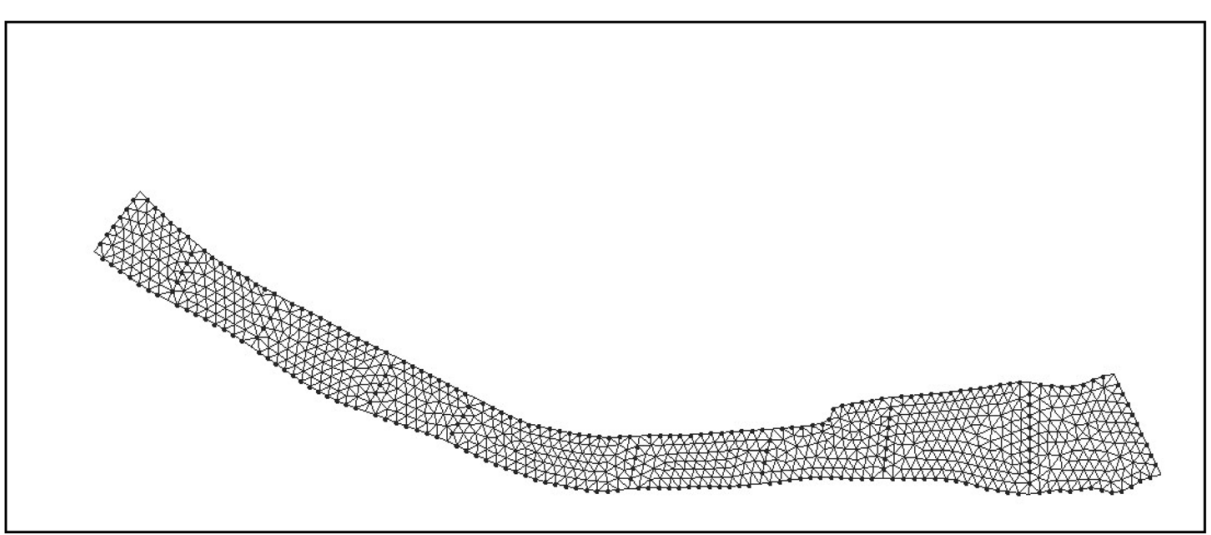

Fig. 7 Arrangement of Grid Network for the Analyzed Section

roughness of the surface as indicated in the manual) was set to 0.030 as river bed materials consisted the mixture of sand and gravel. For the analyzed section, the water level distribution, water depth distribution, flow velocity vector figure and flow velocity distribution figure are presented in the Figs. 8, 9, 10, and 11 based on results of analysis.

The water level distribution for the analyzed section was EL. $4.40 \mathrm{~m}$ to EL. $4.99 \mathrm{~m}$ as shown in Fig. 8, and maximum water level occurred at right bank of section between No. 0 and No. 1 which corresponds to the upstream of analyzed section. In addition, results of numeric simulation showed the changes in water level at each cross-section, which is attributed to longitudinal and cross-sectional spread, the most typical characteristics of 2-dimensional numerical simulation.

The maximum water depth was $4.37 \mathrm{~m}$ which occurred at section between No. 7 and No. 9 in analyzed section as shown in Fig. 9. That is consistent with the geometric spatial distribution figure shown in Fig. 6, and water depth exhibited relatively high value because the maximum depth thalweg was lowest in the analyzed section. The maximum flow velocity was simulated to be $3.25 \mathrm{~m} / \mathrm{s}$ at the section from No. 1 to No. 2 as shown in Figs. 10 and 11. The flow velocity drastically fell by approximately $0.2 \mathrm{~m} / \mathrm{s}$

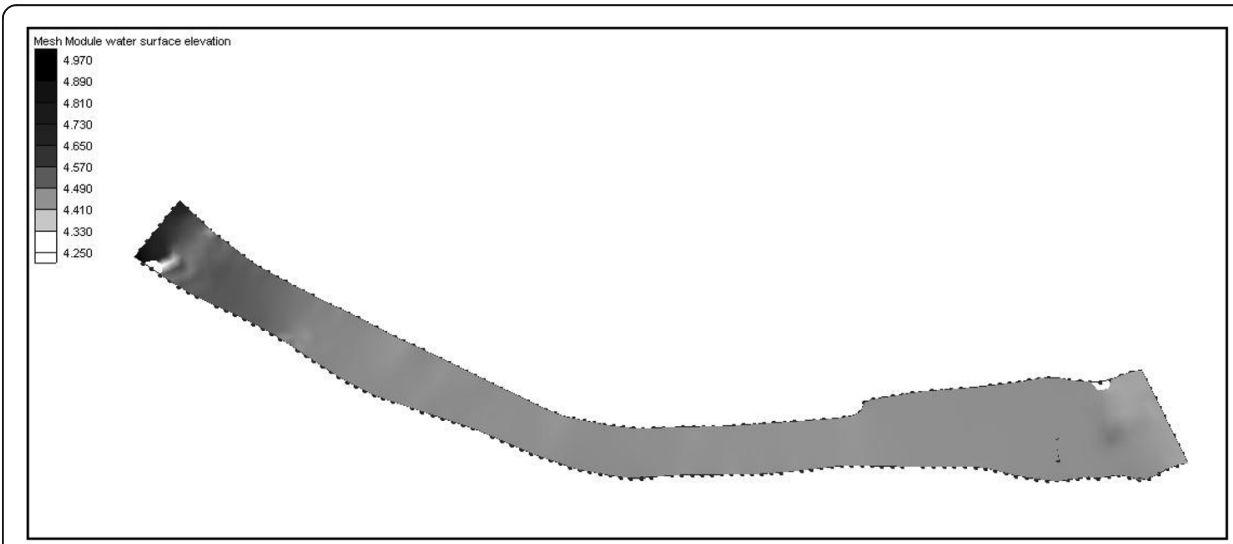

Fig. 8 Water Level Distribution Figure 


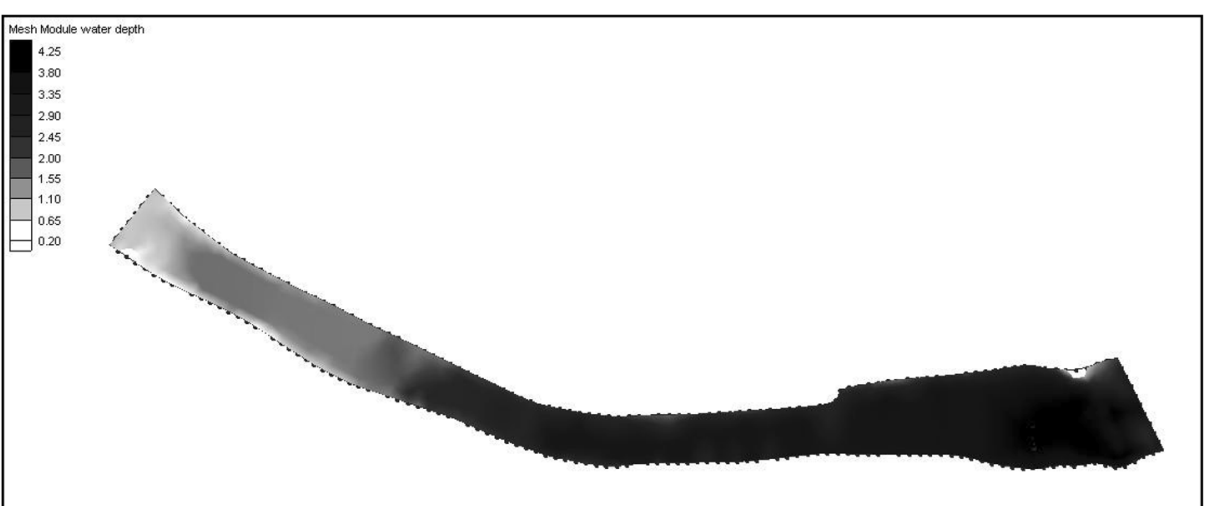

Fig. 9 Water Depth Distribution Figure

because the river width expansion was larger in downstream compared to the upstream as flow traveled to downstream.

The results of simulation showed that the average water level variation based on cross-section was EL. $4.40 \mathrm{~m}$ to EL. $4.75 \mathrm{~m}$ in analyzed section. The maximum flow velocity was $1.89 \mathrm{~m} / \mathrm{s}$ which occurred at No. 2, inlet area of upstream, while the minimum flow velocity was $0.11 \mathrm{~m} / \mathrm{s}$ which occurred at No. 9 .

The mean flow velocity distribution based on cross-section ranged between $0.22 \mathrm{~m} / \mathrm{s}$ and $1.63 \mathrm{~m} / \mathrm{s}$. The maximum mean flow velocity based on cross-section was $1.63 \mathrm{~m} / \mathrm{s}$ which occurred at the cross-section of No. 1, while the minimum mean flow velocity based on cross-section was $0.22 \mathrm{~m} / \mathrm{s}$ which occurred at cross-section of No. 8 .

\section{River bed variation analysis}

The major data fed into the SED-2D model for the river bed variation analysis are daily discharge and suspended sediment amount. The daily discharge was defined as discharge recorded in 1984, year positioned at middle in terms of total discharge. The suspended sediment amount was based on the suspended sediment which was actually

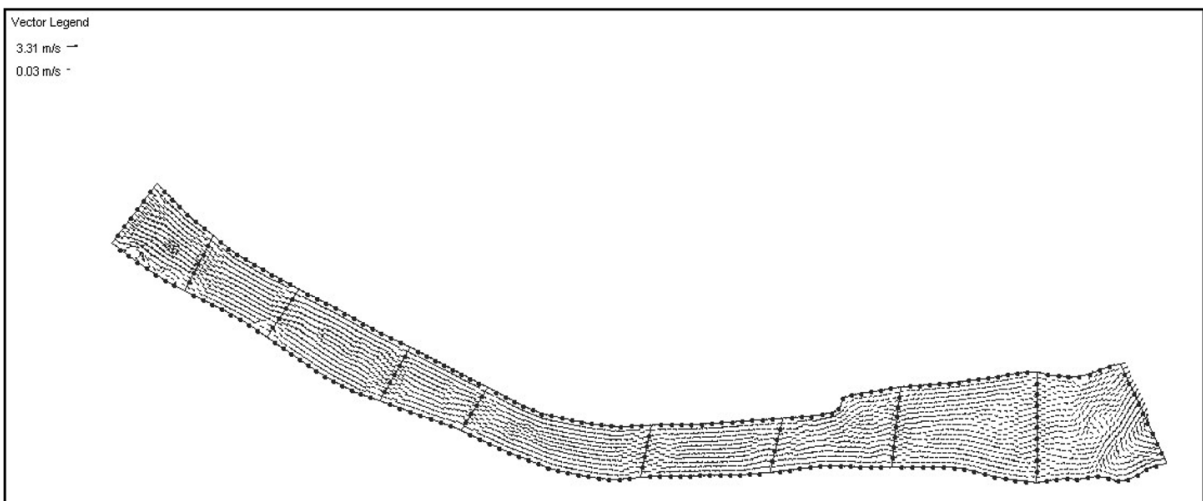

Fig. 10 Flow Velocity Vector Figure 


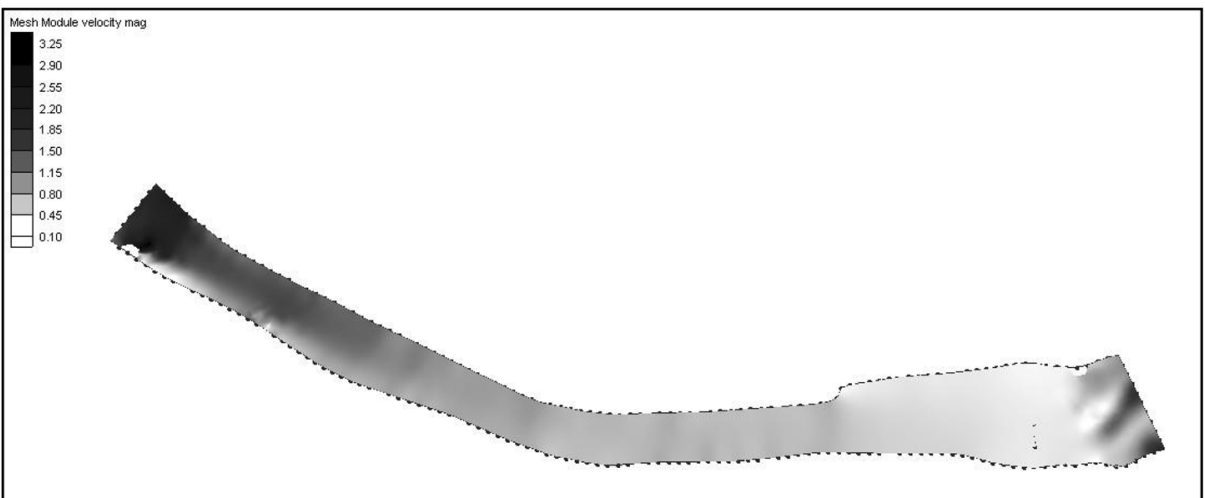

Fig. 11 Flow Velocity Distribution Figure

measured in Geoyeon Stream, a mountain river similar to the Hosan Stream (North Chungcheong Province 2012).

Based on aforesaid conditions, the simulation of river bed variation was performed for 1 year (a total of $8760 \mathrm{~h}$ ) based on SED-2D model. The simulation days was divided into 180 days and 365 days based on the start date and end date of simulation for longitudinal section and cross-section (No. 0 to No. 8) of the Stream. The results are illustrated in Figs. 10, 11 and 12.

Based on the results that have been observed in the 356th day and thereafter since the start of simulation as shown in Figs. 12, 13 and 14, the river bed variation was relatively significant in the upstream, compared to the downstream, in the section from No. 0 to No. 9 as the flow travels to the downstream. The sedimentation of approximately $0.1 \mathrm{~m}$ occurred in the left bank of No. 0 section, while nearly no river bed variation occurred in the right bank. Almost no river bed variation occurred at left bank and right bank of No. 1 and No. 2 sections. However, approximately $0.3 \mathrm{~m}$ sedimentation occurred in the maximum depth thalweg. The maximum sedimentation was approximately $0.42 \mathrm{~m}$ in No. 3 section, which is attributed to the large difference of elevation between left bank and right bank, compared to other cross sections and various facilities installed for the construction of bridge in the vicinity of No. 3 section.

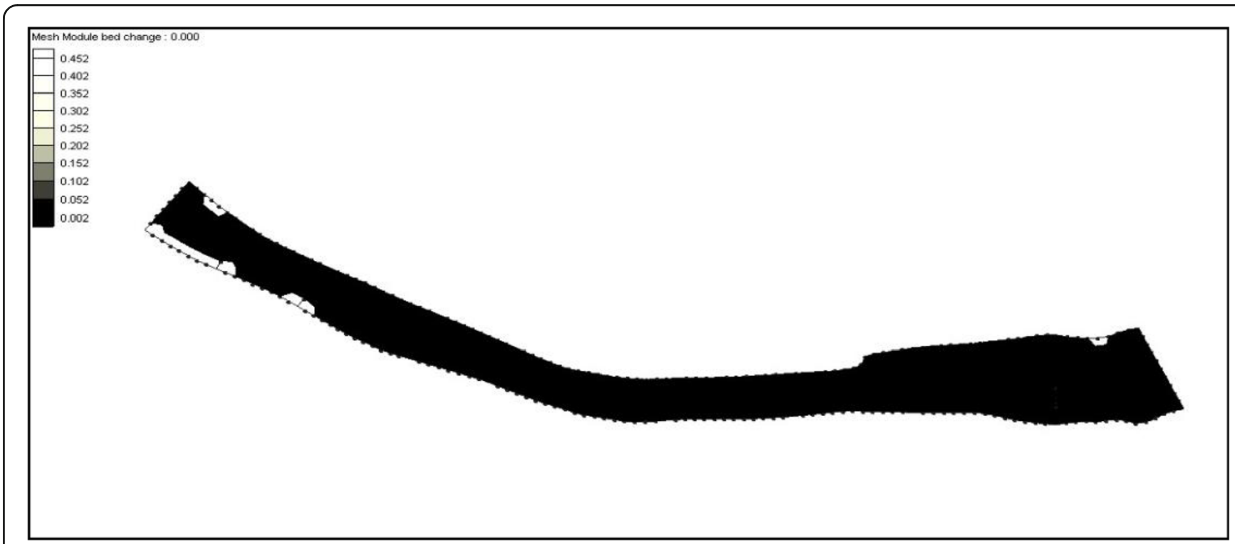

Fig. 12 River bed variation distribution on the start date of simulation 


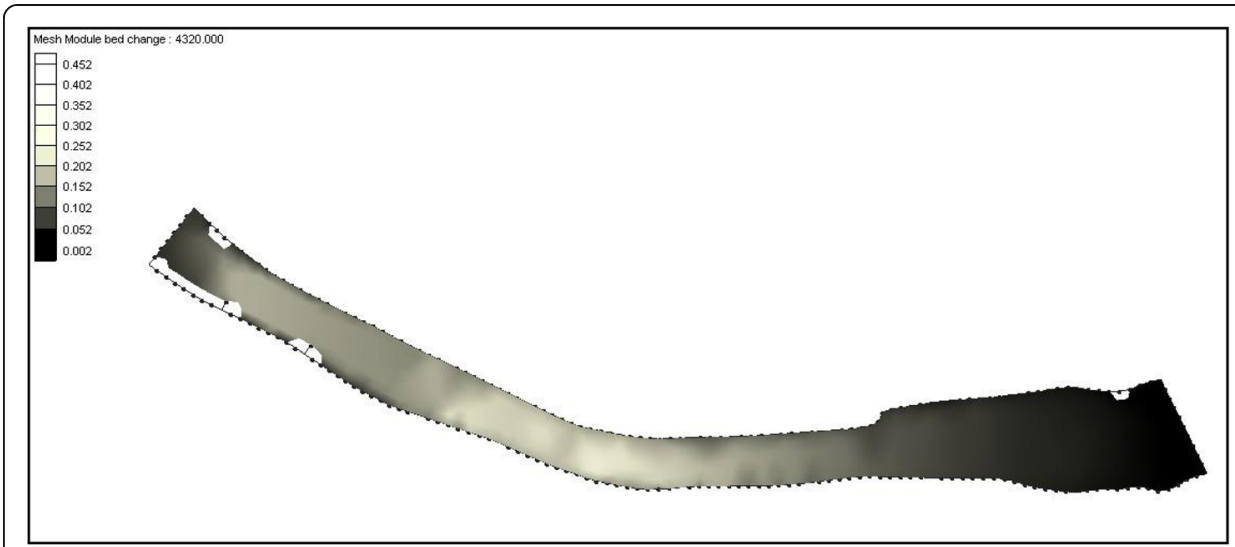

Fig. 13 River bed variation distribution 180 days after the start of simulation

As shown in Figs. 12, 13 and 14, no variation was observed in the right bank of the upstream based on the results of simulation for longitudinal distance of approximately $1.1 \mathrm{~km}$ from the upstream to downstream in analyzed section. The sedimentation of $0.15 \mathrm{~m}$ to $0.30 \mathrm{~m}$ occurred from the No. 3 to No. 6 sections which are the right banks of downstream. Later, the sedimentation of longitudinal section in downstream was found to decrease sharply.

Regarding the variation characteristics of the left bank and right bank of the stream, the downstream showed a decreasing variation compared to the upstream while the sedimentation of approximately $0.2 \mathrm{~m}$ occurred in the upstream.

\section{Conclusion}

In this study, a hydrologic analysis of the Hosan Stream was performed using SSARR, a long-term runoff model, and two-dimensional hydraulic characteristics were analyzed using SMS, a general-purpose program of RMA-2 and SED-2D to simulate twodimensional flow patterns. Results of the hydrologic and hydraulic analysis of the selected watershed are as follows.

For the estimation of flood discharge, abundant water discharge, normal flow, lowwater discharge and drought flow, the simulated runoff of Hosan Stream watershed,

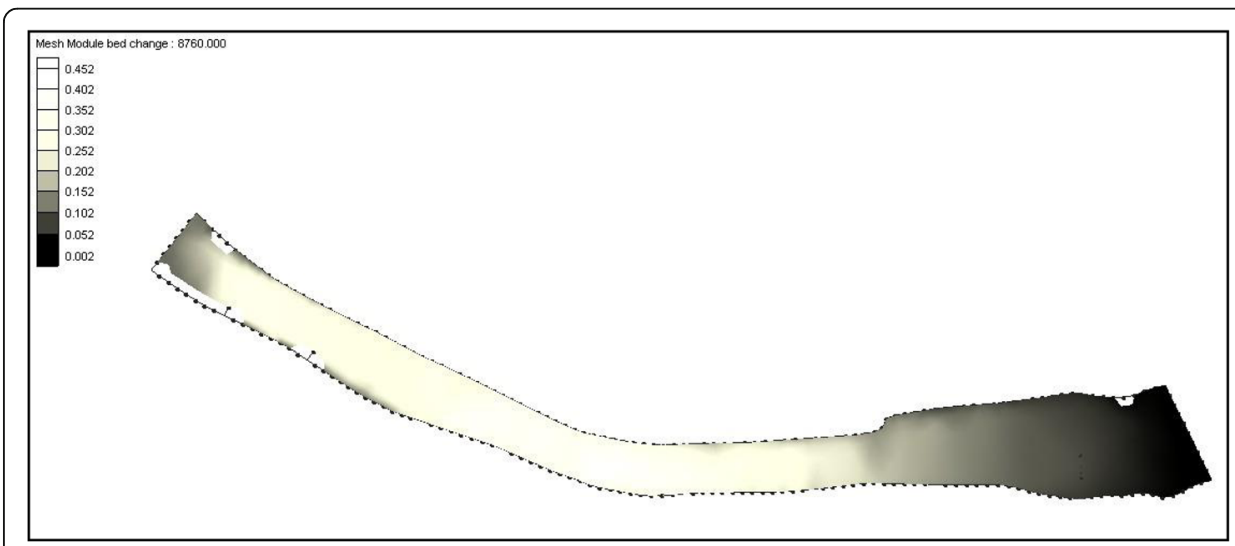

Fig. 14 River bed variation distribution 365 days after the start of simulation 
which was estimated by the SSARR model from 1972 to 2011, was used. The results of simulation on the analysis section using the estimated flood discharge as input data for RMA-2 model showed that the maximum water level and flow rate occurred on the right side in upstream of the section analyzed. As a result of the simulation for 365 days from start date of the simulation using daily runoff of 1984 as input data of SED-2D model, maximum sedimentation occurred in the upstream of the section analyzed.

A comprehensive evaluation of above results revealed that the river width affects flow rate significantly, and the inclusion of sediment in flood flow from the upstream has a huge effect on changes in the riverbed. Therefore, the concentration of sedimentation inflowing from upstream is a very important element in the analysis of riverbed changes when applying the SED-2D model. Measurement of sediment discharge needs to be carried out.

In addition, there is a need to devise measures to mitigate future damage to artificial structures due to flooding by reflecting sedimentation trends of the downstream before construction of large-scale artificial structures in the downstream of the river as in the case of the Hosan Stream.

\section{Acknowledgements \\ $\mathrm{JHH}$ designed, carried out the analysis and wrote the paper. SJM reviewed and edited the manuscript. HSK and SWL provided assistance in the calculations.}

\section{Author contributions}

All of the authors contributed to the conception and development of this manuscript. Ju Ha Hwang designed, carried out the analysis and wrote the paper. Seung Jin Maeng reviewed and edited the manuscript. Hyung San Kim and Seung Wook Lee provided assistance in the calculations. All authors read and approved the final manuscript.

\section{Funding}

Not applicable.

\section{Competing interests}

The authors declare that they have no competing interests.

\section{Author details}

${ }^{1}$ Department of Agricultural and Rural Engineering, Chungbuk National University, 1 Chungdae-ro, Seowon-gu, Cheongju, Chungbuk 28644, South Korea. ${ }^{2}$ Institute of Water Resources Research, K-water,125, 1689-gil Yuseong-daero, Yuseong-gu, Daejeon 34045, South Korea. ${ }^{3}$ Chungbuk Research Institute, 102-1 Daeseong-ro Sangdang-gu, Cheongju, Chungbuk 28517, South Korea.

Received: 16 July 2019 Accepted: 11 November 2019

\section{2.}

\section{References}

Ariathurai R, Krone RB (1976) Finite element model for cohesive sediment transport. J Hydraul Div 102(3):323-338

Duan JG, Julien PY (2010) Numerical simulation of meandering evolution. J Hydrol 391(issues 1-2):34-46

Environmental Modeling Research Laboratory (2003) SMS (Surface Water Modeling System) Tutorials Version 8.1, Brigham Young University.

Han KY, Cho HJ, Son Kl, Kim KS (1993) Analysis of the flood level variation through bridges. J Kor Assoc Hydrol Sci 26(4):3546 (in Korean)

Hongwei F, Minghong C, Qianhai C (2008) One-dimensional numerical simulation of non-uniform sediment transport under unsteady flows. Int J Sed Res 23(4):316-328

Hung MC, Hsieh TY, Wu CH, Yang JC (2009) Two-dimensional nonequilibrium noncohesive and cohesive sediment transport model. J Hydraul Eng 135(5):369-382

Jeong SM, Lim YK, Han KH (2006) An analysis of inflow in Hwacheon dam using SSARR model. Proc KSCE Ann Confer 2006(10):1577-1580 (in Korean)

Korea Meteorological Administration (1999 2011) Annual Weather Report (in Korean)

Korea Water Resources Corporation (2008) Report on the establishment of Han River water system real-time reservoir operation system (development of analytical model) (in Korean)

Lee KS, Kim SU (2001) Automatic calibration of SSARR model with genetic algorithm. J Kor SocCivil Eng 21(3B):171-183 (in Korean)

Lee SJ, Noh JW, Ahn JM, Kim JC (2009) Analysis of hydrologic geo-spatial information using runoff-management model. J Kor Spat Inf Syst Soc 11(1):60-70 (in Korean)

Li SS, Millar RG (2011) A two-dimensional morphodynamic model of gravel-bed river with floodplain vegetation. Earth Surf Process Landf 36(2):190-202 
Maeng SJ, Lee BS (2007) Analysis on hydraulic characteristics in down stream of dam for Fishway construction. J Kor Soc Agric Eng 49(5):11-20 (in Korean)

Nagata N, Hosoda T, Muramoto Y (2000) Numerical analysis of river channel processes with bank erosion. J Hydraul Eng 126(4):243-252

Narut K (1978) Sensibility of parameters of the SSARR model. J Hydraul Res 16(1):1-25

North Chungcheong Province (2012) Basic River Plan Report on Geoyeon Stream (in Korean)

Serrano-Pacheco A, Murillo J, Garcia-Navarro P (2012) Finite volumes for 2D shallow-water flow with bed-load transport on unstructured grids. J Hydraul Res 50(2):154-163

Song JW, Park YJ, Lee YH (1994) Characteristics of channel bend reach and shape of cross-section. J Kor Soc Civil Eng 14(5): 1191-1197 (in Korean)

U.S Army Corps of Engineers (USACE) (1991) SSARR users' manual. North Pacific Division, Portland, USA

\section{Publisher's Note}

Springer Nature remains neutral with regard to jurisdictional claims in published maps and institutional affiliations.

Submit your manuscript to a SpringerOpen ${ }^{\odot}$ journal and benefit from:

- Convenient online submission

- Rigorous peer review

- Open access: articles freely available online

High visibility within the field

- Retaining the copyright to your article

Submit your next manuscript at $\boldsymbol{\nabla}$ springeropen.com 